\title{
O INTERMEDIÁRIO NA ABORDAGEM PSICANALÍTICA DA CUltura ${ }^{1}$
}

\author{
René Kaës ${ }^{2}$ \\ Université Lumière - Lyon 2
}

\begin{abstract}
$O$ artigo discute questões que tratam do mal-estar do mundo moderno e suas agudas transformações que afetam as estruturas familiares, os vínculos intergeracionais, a relação entre os sexos e as estruturas de autoridade e de poder. Estas questões são focalizadas à luz da figura teórica do Intermediário: funções do intermediário no campo da vida social e da cultura.

Descritores: Cultura. Processos sociais. Civilização. Modernidade. Identidade. Grupo. Família.
\end{abstract}

\section{O mal-estar do mundo moderno e as perturbações do intermediário na cultura}

\footnotetext{
$\mathrm{O}$
} malestar do mundo moderno nos confronta com um conjunto de turbulências que afetam as funções do intermediário no campo da vida social e da cultura. Eu evocaria a mutação das estruturas familiares e a fratura dos vínculos intergeracionais; a notável mudança (advinda em apenas duas décadas) nas relações entre os sexos (notadamente no estatuto da mulher); a transformação dos laços de sociabilidade, de estrut uras de autoridade

1 Agradecemos à Casa do Psicológo pela concessão dos direitos editoriais para publicação deste artigo.

2 Endereço eletrônico: renekaes@univ-lyon2.fr 
e de poder; e a confrontação violenta resultante do choque entre as culturas. Todas estas transformações põem em xeque as crenças e os mitos que asseguram a base narcísica de nosso pertencimento a um conjunto social. Elas comprometem os fundamentos da identidade.

Resulta disso que as formas modernas da patologia psíquica não são mais aquelas que, face à neurose da civilização, suscitavam em Freud o desejo de uma psicoterapia nova. A patologia à qual nos referimos concerne cada vez mais freqüentemente à falha (défault) nos processos de apoio, às perturbações da continuidade e das fronteiras de si mesmo, às carências de funções intermediárias e sobretudo das funções mediadoras do préconsciente. À medida que as formações intermediárias não realizam mais seu papel, estas perturbações e estas carências agravam uma série de situações. Falamos das dificuldades de integração das pulsões no espaço psíquico e no espaço social; do excesso de estimulações que põem em xeque a formação do recalque; da violência incontrolada; das perturbações do pensamento e da submissão arrasadora aos ideais arcaicos. A psicopatologia das perturbações da identidade e dos estados-limite está em relação direta com essas falhas das funções intermediárias.

Nesta conferência gostaria de expor como o pensamento psicanalítico nos permite conceber o papel destas funções em relação ao mal-estar no mundo moderno e na cultura.

\section{Algumas referências no pensamento de Freud}

Em 1912-1913, Freud descreveu em "Totem e Tabu" o pacto dos irmãos que se associam para instaurar entre eles uma ordem simbólica. Eles têm sucesso quando substituem o assassinato repetitivo do pai arcaico (perpetrado pela horda) pela organização do grupo que passa, então, a ser estruturado pelos interditos fundamentais: proibição do incesto, interdição de matar o animal totêmico e o irmão. $\mathrm{O}$ pacto que eles selam, sobre o qual se fundam as identificações simbólicas, é uma formação intermediária. Este 
pacto liga, mediatiza e transforma os vínculos sociais e a vida psíquica; ele é gerador dos processos da cultura.

Em 1930, Freud prossegue sua longa meditação sobre o matestar do homem na civilização. Sem a tormenta européia, ele se pergunta por que é tão difícil aos homens serem felizes. A esta questão complexa, ele esboça primeiramente uma resposta simples e geral: se há no homem um mal-estar, isto se deve sobretudo à estrutura conflitante da psique. $\mathrm{O}$ advento do princípio de realidade opera a distinção entre o mundo interno e o mundo exterior. Mas ao encontro deste princípio, o homem inventa satisfações substitutivas, freqüentemente eficazes para compensar as dificuldades da vida; por exemplo, reconstitui sua posição de criança diante de um pai que conheceria todas as suas necessidades.

Freud se interroga, em seguida, sobre as fontes do sofrimento humano. Assinala três: a primeira é a força arrasadora da natureza, a segunda, a fragilidade de nosso corpo, a terceira, a insuficiência de nossos métodos para regular as relações dos homens entre si, no seio da família, do Estado ou da Sociedade (Freud, 1929, p. 444).

Ainda que sejamos obrigados a admitir que a natureza nos arrasa, tentamos, contudo, dominá-la por meio de técnicas; e, mesmo sabendo que nosso corpo está condenado à morte, investimos em atividades superiores, a arte e o pensamento, para tentar, se não evitá-la, ao menos atenuar-lhe o sofrimento. Assim, nos distraímos e mantemos a crença na imortalidade.

Pois bem, Freud constata que nós adotamos uma atitude diferente em relação à terceira fonte do nosso sofrimento, o sofrimento de origem social. Ele escreve:

\footnotetext{
Nós não podemos compreender por que as instituições que nós mesmos edificamos não nos prestariam, a todos, proteção e benfeitorias. De todo modo, se nós refletirmos sobre o fracasso deplorável, precisamente neste domínio das medidas de preservação contra o sofrimento, nós nos apanhamos suspeitando que, ainda aqui, dissimula-se alguma lei da natureza invencível e que se trata, desta vez, da nossa própria constituição psíquica. (1929, trad. fr., pp. 32-33)
} 
Com efeito, a opinião mais difundida é a de que a civilização é responsável por nossa miséria e que deveríamos abandoná-la para retornar ao estado primitivo que nos asseguraria mais felicidade. Tal ponto de vista, hostil à civilização, origina-se daquilo que a vida comum exige e, ao mesmo tempo, contraria a busca do prazer.

Freud (1929) considera que a insuficiência das instituições e de suas funções intermediárias é a responsável por este sofrimento. Ele mostra que, em meio aos traços que caracterizam uma civilização, é decisiva a maneira pela qual são reguladas as relações dos homens entre si:

O elemento civilizado seria dado pela primeira tentativa de regulamentação das relações sociais (...). A vida em comum para os homens só se torna possível quando uma pluralidade consegue se reunir em um conjunto mais poderoso que cada indivíduo particular, e tem sucesso em se manter conjuntamente face a todo indivíduo particular.

Toda análise de Freud converge em direção à necessidade da renúncia à realização direta dos fins pulsionais. Esta renúncia é o que se deve perder em relação ao prazer para que o vínculo possa se formar e se manter. Este é um postulado fundamental: a civilização é construída sobre a repressão das pulsões e sobre a renúncia:

(...) cada indivíduo cedeu uma parte de sua propriedade, de seu poder de soberania, de tendências agressivas e vingativas de sua personalidade. É destas contribuições que provém a propriedade cultural comum dos bens materiais e dos bens ideais. Além das exigências da vida, são os sentimentos familiares advindos do erotismo que levaram os indivíduos, tomados isoladamente, a esta renúncia.

"O Mal-Estar na Civilização" coloca em evidência uma segunda linha de reflexão. Ela diz respeito às compensações e ao contrato obtidos em troca da constrição e da renúncia. "O homem civilizado trocou uma parte de felicidade possível por uma parte de segurança" (Freud, 1929, p. 474), escreve Freud:

O resultado final deve ser a edificação de um direito ao qual todos, ou ao menos todos os membros suscetíveis de aderir à comunidade, que têm contribuído ao sa- 
crificar sua impulsão instintiva pessoal, não devem deixar nenhum dentre eles se tornar vítima da força brutal, com exceção daqueles que não aderiram.

A comunidade de direito tem como condição a comunidade de renú ncia à realização direta dos fins pulsionais. Sobre esta base, ela protege contra a violência do indivíduo, impõe a necessidade e torna possível o amor. Ela garante a cada um a segurança necessária para a formação do pré-consciente, para o trabalho do pensamento e a manutenção dos vínculos (laços).

\section{O pensamento do intermediário em G. Róheim}

A noção de objeto intermediário em Géza Róheim é um elemento central de sua teoria do psiquismo e da cultura. Róheim encontra sua inspiração em duas correntes de pensamento: em Freud e na escola húngara, notadamente em I. Hermann.

Apóia-se sobre os trabalhos de Freud quando este faz referência à descoberta do jogo do carretel, onde a criança utiliza o carretel como substituto da mãe e como representante de um movimento psíquico de oscilação entre a rejeição (rejet) e o reencontro do objeto.

Róheim revigora as bases destas observações freudianas ao se apoiar nas pesquisas de Hermann sobre os conceitos de unidade dual, de agarramento (agrippement) e de busca; isto é, sobre os conceitos que dão conta da perda do objeto e dos processos de separação. Róheim define o objeto intermediário pelo seu aparecimento em um processo. $\mathrm{O}$ objeto intermediário é um momento de estabilização na oscilação entre um movimento de agarramento e um movimento de busca. Róheim escreve:

O grande valor destes objetos reside em sua dualidade, no fato de se situarem entre o amor objetal e o narcisismo; eles são ego-sintônicos e libidinais, sociais e individuais, condutores de emoção de extraversão e de introversão. Eles representam uma grande segurança obtida pelos homens em sua luta contra o risco da perda do objeto. Eles são, ao mesmo tempo, uma parte deles mesmos e um representante dos seres que eles amam (...). E, na medida que os objetos correspondem às mesmas tendências nos outros ou representem estas tendências, eles constituem a base libi- 
dinal da cooperação social. Erigidos como proteções contra os perigos imaginários do psiquismo infantil, eles se tornam os instrumentos utilizados pela nossa espécie infantil em sua luta com a realidade. (1943, ed. fr. 1972, p. 147)

O objeto intermediário mantém a ligação entre os objetos separados, "entre o morto e o vivo". O objeto intermediário é um produto de Eros, é obra de criação, de ligação, de articulação unificante. Mas ele é, primeiramente, a saída da experiência de separação inaugural, experiência crucial, ligada ao retardamento específico do recém-nascido humano, ao nascer (tese de Bolk). O objeto intermediário passa a ter um valor determinante para a pesquisa posterior do que constituirá o equivalente de uma garantia contra o risco desta separação. Tais são o dinamismo e a origem conjunta do desenvolvimento da vida psíquica, da cultura e da civilização.

A definição que Róheim propõe sobre a civilização resulta destas considerações: "A civilização tem sua origem na infância retardada e sua função é de segurança. É um gigantesco sistema de tentativas mais ou menos felizes para proteger a humanidade contra o perigo da perda do objeto."

Este esforço vital torna-se possível pelo processo de sublimação. Róheim nos lembra da teoria de Freud sobre o papel que o ego (Moi) tem na sublimação e da distinção feita por Ferenczi entre duas tendências da libido: uma dirigida ao objeto, a outra refluída do objeto em direção ao corpo. A sublimação se efetua "pelo intermediário do ego (Moi), transforma a libido sexual dirigida ao objeto em uma libido narcísica e lhe impõe fins diferentes".

Neste ponto Róheim retorna ao ponto de vista de Hermann a propósito do antagonismo complementar entre a pulsão de agarramento que visa a reencontrar a mãe e manter a unidade dual, e a pulsão de busca que visa a procurar novos substitutos maternais. Destas pesquisas, Róheim retém a idéia de uma oscilação entre a atitude narcísica e o movimento de busca do objeto. Ele escreve: "Na sublimação esta oscilação deve desaparecer e ser substituída por alguma coisa mais estável” (p. 118). Esta estabilização corresponde ao objeto cultural e, mais extensamente, à cultura. A sublimação é um equivalente da cultura e Róheim insiste sobre o aspecto social da mesma: "Na sublimação, alguma coisa de novo é criada - uma casa ou uma 
comunidade ou um instrumento - e isto é criado no seio de um grupo ou para o uso de um grupo" (p. 116).

Entre as idéias desenvolvidas por Róheim, há uma que será retomada vinte e cinco anos mais tarde por Winnicott. Esta idéia, que ele mesmo toma emprestada de C. Wissler (1923), é a de que a civilização e a cultura são elaborações resultantes do modo pelo qual o homem "brinca com os brinquedos que ele cria com a maior seriedade” (Róheim, 1943, ed. fr. 1972, p. 120).

\section{A noção de espaço cultural em D. W. Winnicott}

Em meados do século passado, D. W. Winnicott inventa as noções de fenômeno, de objeto e de espaço transicionais. Primitivamente constituído pela mediação que a mãe estabelece entre as necessidades psíquicas e corporais da criança e o meio psíquico e social que a envolve, este espaço vai rapidamente se qualificar como o espaço da cultura.

Com efeito, vinte anos mais tarde, Winnicott escreve:

(...) eu empreguei o termo experiência cultural vendo nele uma extensão das idéias de fenômenos transicionais e de brincar (jeu) (...). Ao utilizar o termo cultura, penso na tradição que herdamos. Eu penso em alguma coisa que é o lote (lot) comum da humanidade ao qual os indivíduos e os grupos podem contribuir, e de onde cada um de nós poderá retirar alguma coisa, se nós tivermos um lugar onde colocar o que nós encontramos. (1975, p. 99)

Para Freud, como para Wissler e Róheim, a cultura é uma formação e um processo intermediário.

Ao articular a área transicional e o espaço cultural, Winnicott nos permite pensar a relação entre o mundo interno e o mundo dos signos, do sentido e dos ritos estabelecidos em comum, sem torná-los mutuamente excludentes, mas, ao contrário, admitindo sua intrincação.

O que é próprio da área transicional e da localização cultural que deriva dela, é fazer co-existir, sem crise nem conflito, o que já estava lá e o que 
ainda não surgiu, a herança e a criação. Esta co-existência é um momento paradoxal e fecundo que supõe uma experiência subjetiva e intersubjetiva de tolerância e de confiança. Cada um destes espaços é primeiramente o lugar de uma experiência fundadora. A experiência da ilusão de uma continuidade entre a realidade psíquica e a realidade externa, entre aquilo que se herda e aquilo que se encontra e cria. Com efeito, a simbolização e a criatividade que introduzem a experiência cultural só podem se produzir - como Winnicott (1975) diz: "se nós tivermos um lugar onde colocar aquilo que encontramos".

Pois bem, o que nós procuramos estabelecer até agora é que o malestar do mundo moderno se deve, por uma parte, à deficiência ou à ausência dessas formações intermediárias, porque não dispomos suficientemente nem de processos que nos introduzam na experiência cultural, nem do lugar "onde colocar aquilo que encontramos". Tentemos agora situar algumas características do malestar do mundo moderno, tornando mais precisas algumas idéias que esbocei.

\section{Algumas características do mal-estar do mundo moderno}

Aquilo que chamamos de pós-modernidade generalizou as experiências da transplantação, do exílio e do desenraizamento: ela acentuou a violência. Nesta experiência, nós somos confrontados não somente com o que há de estranho (estrangeiro) no outro, mas, primeiramente e sobretudo, com o que surge em nós de desconhecido, de indiferenciado e de estranhamento inquietante. Nossas referências identificatórias e nossas identificações se encontram modificadas. Nesta perspectiva, as falhas (failles) na segurança do ambiente são também uma experiência geradora de angústia, na medida em que a perda do código reatualiza os conflitos intrapsíquicos entre as tendências de amor e de ligação e as tendências de raiva e de desligamento.

Algumas análises de etnopsiquiatria africana poderiam ilustrar este assunto. Elas mostram como a transformação das sociedades africanas tradicionais - após a colonização européia - modificou os papéis e os estatutos 
instituídos na organização dos grupos primários, sobretudo na organização da família. Essas organizações também mostram que as bases de adesão e a crença nos sistemas de representação tradicionais foram abaladas, atacadas ou destruídas.

Nos sistemas em equilíbrio suficiente - como poderiam ser as sociedades tradicionais - a autoridade não era discutida. Ela era integrada em um conjunto onde cada indivíduo tinha seu lugar, seupapel e seu status de modelos imutáveis ou relativamente estáveis. A autoridade garantia o lugar de cada um, seu papel, seu status e a ordem social que derivava deles. Ela garantia assim a segurança de cada um.

Em um sistema como este, quando desaparecia uma figura portadora de autoridade, não havia, em geral, consequiências graves. Isto porque era sempre possível transmitir, receber e integrar valores em razão da solidariedade comunitária e da estabilidade da cultura. Dito de outro modo, a renú ncia pulsional e, se nós utilizarmos os conceitos que eu propus, o contrato narcísico e as alianças inconscientes garantiriam a estabilidade do conjunto e a estabilidade psíquica de cada um. Após os movimentos da colonização, quando a industrialização se desenvolve e se instala o urbanismo, a estabilidade destes sistemas sofre uma violência e se racha: o grupo primário se desagrega e, com ele, os códigos socioculturais são perturbados. Nestas condições, a relação do indivíduo ao grupo está ameaçada e, por isso mesmo, sua segurança. Esta desculturação tem consequiências desorganizadoras sobre as defesas psíquicas socialmente organizadas entre os indivíduos, sobre o que nós poderíamos chamar, seguindo Elliott Jacques, de meta-defesas.

Com efeito, o pensamento mágico e a feitiçaria têm como suporte sistemas sócio-culturais estáveis e intactos. Por sua vez, estes processos e estas formações (a magia e a feitiçaria) constituem mecanismos de auto-regulação individuais e coletivos que limitam o desenvolvimento da patologia.

$\mathrm{Na}$ África, a feitiçaria é uma das respostas dadas pela sociedade ao problema da existência do mal e da doença. A doença é concebida como resultado de relações perturbadas no que se refere à ordem estabelecida ou a vários membros do grupo. Ela é o resultado de dificuldades graves com a 
regra que rege a comunidade, regra que implica os ancestrais e que contém todos os interditos. A feitiçaria tem um papel de regulação individual e social, já que ela permite, ao mesmo tempo, localizar a origem do mal (quer dizer, aquilo que ataca a coesão do grupo) e de exorcizá-lo (quando o curandeiro expulsa ou destrói aquele que é o portador do mal). Ela permite assim suprimir a angústia suscitada pela ausência da localização do mal e retomar a ordem da família, do grupo e do conjunto social.

As sessões de cura, de terapia tradicional consistem, na África, na reintegração do indivíduo doente ao grupo familiar. Eles são reunidos e reunificados no mesmo movimento que realiza, novamente, a unidade do sujeito. A doença aparece, então, como uma saída proposta pelo grupo ao conflito entre seus membros. Pode-se aqui fazer uma leitura sistêmica do "paciente identificado" como portador de um efeito de regulação de conflitos no interior do grupo. Ele é, dessa forma, o sintoma da desordem no grupo ao mesmo tempo em que é a cura desse sintoma.

Quando os grupos de base se desorganizam ou são destruídos, nós podemos compreender que o recurso aos modos de defesa tradicionais (pensamento mágico, feitiçaria, projeção sobre o exterior) se tornam inoperantes. Esta pane (déffaillance) está diretamente implicada na gênese de perturbações graves da percepção da realidade. Com efeito, o indivíduo desculturalizado em seu grupo e a autoridade desqualificada frente ao grupo são privados do ambiente tradicional que permitiria a utilização dos mecanismos de projeção da angústia e da culpa sobre o grupo e o feiticeiro. A autoridade, ao invés de garantir o lugar e a ordem no grupo (e por isso mesmo as instituições da segurança), torna-se o único cimento da última coesão familiar e pessoal. Mas, quando a autoridade se torna muito coercitiva, surgem novos problemas, pois ela não terá mais efeito positivo; não transmite mais nada, devido ao empobrecimento dos valores tradicionais que ela garante. Ao se fixar, a autoridade se torna um obstáculo a uma eventual evolução, ela interdita a expressão e a superação dos conflitos. A afirmação da autoridade não gera mais um espaço de crescimento psíquico e social. É isto que quer dizer auctoritas. Vemos assim um círculo vicioso se manifestar. A autoridade sem outra finalidade que ela própria, aprisiona o indivíduo em um número limitado 
de papéis, empobrece sua personalidade e não desenvolve nenhuma plasticidade adaptativa. $\mathrm{O}$ grupo primário não pode mais assumir suas funções organizadoras da personalidade e veicular os valores da tradição.

A doença é, então, uma das raras soluções possíveis, não importando qual é o tipo de perturbação. Os etnopsiquiatras da Escola de Dakar, no Senegal, impulsionados por terapeutas tradicionais e terapeutas formados à moda européia, cujo líder foi Henri Colomb, mostraram que o recurso ao episódio delirante (bouffée délirante) aparece, então, como o tipo dominante de patologia. O episódio delirante (bouffée délirante) não é somente uma perturbação grave da organização psíquica, ele é também uma saída, uma criação encontrada pelo sujeito quando a coesão grupal é destruída ou ins uficiente. $\mathrm{O}$ episódio delirante (bouffée délirante) permite freqüentemente um reajuste da personalidade às novas condições de existência. Isto pode se dar graças à hospitalização, quer dizer, graças à ajuda de uma estrutura intermediária e de um grupo transicional. No hospital que eles criaram em Dakar, o Hospital Fann, estão reunidos terapeutas tradicionais que conhecem bem o modo de funcionamento dos psiquiatras europeus, e psiquiatras que conhecem bem o modo de trabalho dos psicoterapeutas tradicionais. Sem dúvida, vocês também dispõem de modelos análogos nas suas próprias estruturas de tratamento, onde estão associadas diferentes culturas e abordagens.

Se, neste ponto, nós não mais olharmos com o efeito de exotismo que essa situação produz, inevitavelmente, talvez com a ilusão etnocêntrica que produz este tipo de reflexão; se, neste momento, voltarmos nosso olhar em direção à nossa própria sociedade, podemos constatar igualmente perturbações graves de referências identificatórias e uma fraqueza (défaillances) identitária nos jovens das sociedades industriais e pós-industriais. Estes são os efeitos sociais e psíquicos da pós-modernidade. Em parte, as dificuldades da construção identitária se referem à desorganização das referências simbólicas; desorganização esta que está sob o efeito do desaparecimento da lei e dos dispositivos de elaboração dos conflitos gerados por ela. Dito de outro modo, a possibilidade de transformar a relação com a lei, através dos recursos de arbitragem, desaparecem ou está em vias de desaparecimento. Disto 
resulta uma acentuação das tendências anômicas e correlativamente uma desestruturação do espaço psíquico.

A identidade se constrói através de dois processos distintos e articulados:

$1^{\circ}$. A partir de representações e de enunciados fundamentais, próprios do conjunto humano, e que sustentam nos sujeitos desse conjunto os interditos, as certezas e as crenças dos quais os contratos coletivos e os mitos são as garantias. Em meio a estes contratos coletivos, eu integro o contrato de renuncia mútua à realização dos fins pulsionais, e incluo, igualmente, o contrato narcísico e as alianças inconscientes, notadamente o pacto denegativo. Esta primeira via de construção da identidade se forma a partir das representações e dos enunciados fundamentais que repousam sobre estes contratos coletivos e sobre os mitos que garantem: "os enunciados de certeza" (Aulagnier, 1979), as crenças e os interditos.

$2^{\circ}$. A partir, também, das representações reenviadas ao grupo, do exterior, pois a identidade se constrói não somente de uma maneira, interna a um grupo. Estas representações são importantes, pois elas trazem como efe ito a diferenciação entre o dentro e o fora. Distinção que, por sua vez, operará uma afirmação identitária por espelhamento. Nossa identidade é ao mesmo tempo definida a partir de dentro dos nossos grupos (de pertencimento), mas, também, pelo que os outros nos reenviam. Existe uma distância (écart) entre a nossa identidade tal como ela é definida parcialmente no conjunto ao qual nós nos identificamos (e que nos reconhece como seus membros) e a representação que é reenviada do exterior. É o problema do encontro intersocial e inter-cultural.

As dificuldades surgem quando as representações identitárias são inconsistentes. Às vezes, porque os contratos e os mitos que as garantem e que as sustentam não são mais dados como certos e porque a valorização intragrupal só se efetua pela desvalorização ou pela supervalorização da alteridade externa. Este duplo processo é acompanhado de uma desvalorização narcísica e, então, de uma rejeição (rejet) da identidade e da alteridade. Este tipo de situação caracteriza, em larga medida, as dificuldades da mestiçagem nas sociedades urbanas contemporâneas. Ela caracteriza os grupos étnicos 
aculturados, heterogêneos e segregacionistas que reúnem, por exemplo, o que nós chamamos na Europa dos jovens imigrantes "de segunda geração" e nos quais funcionam representações e identificações sobrepostas (bricolées), contraditórias ou paradoxais.

Face a uma situação caracterizada pelas representações identitárias insuficientes e inconsistentes que demandam uma desvalorização correlativa do outro, podemos descrever várias condutas. Uma delas é a busca de uma solidariedade comunitária que encontra hoje, no tribalismo e nos movimentos sectários, suas expressões mais marcantes. A afirmação comunitária é um testemunho da crise profunda das identidades e da dessocialização. Trata-se de grupos-refúgio, onde o agarramento (agrippement) ao grupo prevalece. São grupos que se caracterizam por se fecharem em si mesmos, pela busca de uma proteção nas relações internas, de um clima de calor que reconstitui as características de um ninho primitivo. Em relação ao mundo exterior, três atitudes se desenvolvem: um desinteresse total pela sua existência; sua recusa (rejet) agressiva em razão proporcional ao enclausuramento dos indivíduos na estrutura comunitária do grupo e, finalmente, uma tentativa desesperada de controle social integral, freqüentemente justificada pela ameaça de catástrofes planetárias.

De modo oposto a estas organizações estruturadas, um movimento de aglutinação de indivíduos em grupos informais de pares desenvolve uma sociabilidade minimalista, profundamente individualista, na qual cada um vive do lado do outro e não com ele. Em alguns sujeitos a reivindicação de individualidade é tanto mais intensa quanto maiores forem as forças de dissolução na massa. Penso aqui nas pesquisas conduzidas por V. Colin na minha universidade. Ela trabalhou sobre o modo de sociabilidade das pessoas que vivem na rua em Lyon, e que recorrem a este tipo de aglutinação. As pessoas sem domicílio fixo não formam um grupo verdadeiro, elas, porém, estabelecem entre si um mínimo de laço frente a certos perigos ou para garantir certas funções vitais. Mas o essencial de suas relações não é nem estável nem permanente. Em todos estes casos, não há propriamente uma identidade coletiva, a consciência de pertencer a um mesmo conjunto é quase inexistente, não há identidade coletiva fundada sobre identificações mútuas. 
Um outro indigente não é reconhecido exatamente como um outro de fato, "é um outro, e eu não tenho nada a ver com ele". Não há tampouco consciência de adversários sociais, o que poderia ser o embrião de uma consciência política. Conseqüentemente, se não há adversários sociais, não há identificação correlativa de si e do outro. Eu penso aqui na noção de adversário no sentido em que Freud fala nas primeiras linhas de "Psicologia de Grupo e Análise do Ego", onde ele define o outro como sendo, ao mesmo tempo, um aliado, um adversário, alguém em quem possamos nos apoiar e com quem possamos nos identificar. Não há outros nestas organizações. Os conflitos não são localizáveis e, quando eles surgem, exprimem-se em explosões efêmeras, em expressões esporádicas, individuais ou coletivas, mas não chegam a formar um processo de crise, no sentido de uma organização durável. Evita-se, assim, a continuidade de um movimento organizador.

\section{O simbólico: a formação do sentido e o trabalho do pré-consciente}

Gostaria agora de desenvolver algumas considerações sobre as perturbações que atingem o processo representacional, a construção do sentido e os dispositivos interpretativos no makestar do mundo moderno. Trata-se de perturbações das funções e das estruturas intermediárias e do jogo (jeu) transicional. Estas perturbações afetam particularmente a atividade do préconsciente, quer dizer, o lugar tópico da formação dos processos e das construções intermediárias. Sobre esta base, nós podemos dizer que estas perturbações afetam igualmente o processo de sublimação e o trabalho da simbolização primária. Estas perturbações estão sempre como um pano de fundo das perturbações da separação precoce e dos traumatismos cumulativos e sobredeterminados. Estão, também, como um pano de fundo dos lutos coletivos difíceis, consecutivos às catástrofes ditas naturais, como os tremores de terra, a explosão de uma usina química ou as inundações. Claro que estas catástrofes se distinguem das catástrofes intencionais (guerra, violência de estado, genocídios), mas nós podemos admitir que em certas catástrofes 
"naturais" uma dimensão política está em jogo (ecologia, prevenção) e, além do mais, seus efeitos não são indiferentes à organização social.

Freud descreveu o pré-consciente como o sistema do aparelho psíquico no qual se efetuam os processos de transformação que certos conteúdos e processos inconscientes sofrem para retornarem à consciência. A capacidade associativa e interpretativa, vital para a psique, está inserida neste sistema. É neste sentido que a função do pré-consciente é fundamental na atividade de sublimação e na simbolização.

Nas minhas pesquisas, tentei evidenciar como o sistema, os processos e as organizações do pré-consciente, descritas por Freud do ponto de vista intra-psíquico, são parcialmente dependentes da vida psíquica do outro. A própria atividade e formação do pré-consciente dependem, em parte, do préconsciente do outro, de sua capacidade de rêverie (tal como a descreveu Bion), de sua capacidade de conter e de transformar certas formações psíquicas do outro. A função de acompanhar pela fala (parole) as experiências da criança, tal como a realiza a mãe em sua função de porta-voz (tão bem descrita por Piera Aulagnier), é o modelo que nos permite compreender como a formação do pré-consciente do infans é dependente do pré-consciente do outro, do outro maternal. O pré-consciente da mãe é uma parte integrante do aparelho para significar-interpretar que se constrói no bebê.

Eu abro aqui um parêntese para dizer por que eu utilizo a noção de aparelho para significar-interpretar. Nas últimas páginas de "Totem e Tabu", Freud imagina que cada um dentre nós construiu em sua psique o que ele chama de "ein Apparat zu deuten", um aparelho para interpretar, mas também para significar, produzindo signos e significantes. Este aparelho para interpretar-significar é o aparelho que nos permite entrar em comunicação e transformar as percepções conscientes do outro no nosso próprio sistema de interpretação-significação. É neste texto que eu encontrei a primeira formulação psicanalítica do duplo processo de construção do pré-consciente. Freud o descreveu em sua primeira tópica como uma forma puramente intrapsíquica, mas, com a noção de aparelho para significar-interpretar, ainda que ele não faça a relação com o pré-consciente, ele nos abre uma outra via. A- 
inda que ele não tenha podido testar sua intuição através de dispositivos metodológicos adequados, este aparelho testemunha sua preocupação em compreender como a vida psíquica do sujeito se organiza com a vida psíquica do outro. Eu darei um exemplo: em "Três Ensaios Sobre a Teoria da Sexualidade", Freud (1905) comenta, em uma nota de rodapé, como a pulsão oral da criança se forma no contato com a experiência de prazer da mãe. Temos aqui um novo argumento para introduzir o efeito da psique do outro na estruturação intra-psíquica da experiência de prazer-desprazer, de apoio (étayage) da pulsão na formação do recalque e do pré-consciente.

\section{O pré-consciente, o traumatismo, o acting, violência e raiva do pensamento}

As patologias do pré-consciente só podem ser tratadas e compreendidas na medida em que o trabalho do pré-consciente do outro (essencialmente por sua atividade de colocar em palavras e em fala endereçada a um outro) restabelece as condições de uma retomada da atividade de simbolização. Nós podemos considerar as patologias do traumatismo como uma das grandes fontes do sofrimento contemporâneo. Trata-se sempre de patologias conjuntas do narcisismo, dos contratos intersubjetivos e dos espaços intermediários ou da transicionalidade. Estes traços são comuns a diferentes tipos de população: populações de psicopatas, certas categorias de desempregados de longa duração e pessoas traumatizadas sob o efeito da violência social e política. Claro que há diferenças a serem traçadas dentro destas categorias, mas estou tentando apenas destacar um elemento que elas têm em comum.

A falência (la mise em faillite) do pré-consciente tem como efeito a introdução de uma confusão entre o dizer e o fazer, entre a ação e a representação. Os mesmos efeitos operam nos laços (vínculos) inter-subjetivos. O traumatismo auto-sustentado mantém a confusão dos sujeitos entre si, mas também os conjuntos intersubjetivos em excitação de crise permanente, porque as formações intermediárias estão falhando (défaillantes). A crise atinge primeiramente as zonas de contato e de passagem: do dentro e do fora, do intra-psíquico e do inter-psíquico. Estas zonas de passagem e de contato são 
zonas de dissociação e de desmoronamento (effondrement) homólogas no espaço intra-psíquico e no espaço inter-subjetivo.

Nesta perspectiva, a relação entre as falhas (défauts) do préconsciente, os actings violentos e a raiva do pensamento são uma constante. Não pensar, responder à urgência da situação com a violência do ato evita o sofrimento de pensar o vínculo de violência. $O$ vínculo de violência é mantido para criar um estado de não pensamento: a ameaça mútua, a onipotência e a provocação à busca de limites são os elementos pelos quais a raiva se encontra constantemente mobilizada. Gritar bem forte, bater, agir, insultar são as modalidades que põem a vida psíquica fora do circuito e cumprem a exigência de não pensar. Uma irritação lábil ou permanente engendra, em um movimento circulatório auto-alimentado, o medo, a raiva, a ferida narcísica que não se cicatriza. A raiva solda um grupo que se refere somente a si mesmo, e torna particularmente difícil separar-se e se diferenciar. As funções de colocar em latência e de representar a fala ficam paralisadas ou inexistentes. Além disso, a cultura do imediatismo, com um horizonte temporal curto, mantém a excitação e orienta a descarga pulsional em direção ao acting-out.

Nós poderíamos abrir um debate sobre os efeitos da sociedade de consumo rápido e sobre a incitação a manter uma excitação frente ao objeto que será somente um objeto de necessidade (besoin) e que não poderá ser elaborado como um objeto de renúncia, quer dizer, de desejo.

\section{Sofrimentos no mundo moderno e fragilidade das estruturas intermediárias}

As estruturas psíquicas intermediárias são particularmente frágeis. São estruturas "plásticas", extremamente sensíveis às transformações. As novas formas do malestar do mundo moderno ameaçam estas estruturas. Pois bem, estas estruturas psíquicas intermediárias são também estruturas da transmissão da vida psíquica. A formação destas atividades psíquicas mostram, no mais alto grau, as exigências de trabalho psíquico imposto pelo trabalho da cultura. 
O que eu chamei Análise Transicional diz respeito e opera sobre os processos e as formações intermediárias abaladas, rompidas pela crise dos fundamentos sociais e inter-subjetivos da vida psíquica. Pois bem, termino aqui o que eu queria falar-lhes esta manhã.

Kaës, R. (2003). Intermediary in psychoanalytical approach of the culture. Psicologia USP, 14(3), 15-33.

\begin{abstract}
This article discusses issues related to the discontents of the modern world as well as the acute transformations which affect family structures, inter-generational bonds, the relationship between genders and the structures of power and authority. These issues are focused in the light of the theoretical concept of Intermediary: functions of the intermediary in the field of social life and culture.
\end{abstract}

Index terms: Culture. Social processes. Civilization. Modernity. Identity. Group. Family.

Kaës, R. (2003). L'intermédiaire dans l'abordage psychanalytique de la culture. Psicologia USP, 14(3), 15-33.

Résumè: L'article discute les questions traitant du malaise du monde moderne et ses transformations importantes qui affectent les structures familiales, les liens entre générations, la relation entre les sexes et les structures d'autorité et de pouvoir. Ces questions sont étudiées à la lumière de la figure théorique de l'intermédiaire : fonction de l'intermédiaire dans le champ de la vie sociale et de la culture.

Mots-clés: Culture. Processus sociaux. Civilisation. Modernité. Identité. Groupe. Famille. 


\section{O Intermediário na Abordagem Psicanalítica da Cultura}

\section{Referências}

Aulagnier, P. (1979). Les destins du plaisir. Aliénation - amour - passion. Paris: PUF.

Freud, S. (1905). Drei abhandlungen zur sexualtheorie. Gesammelte Werke (Bd. 5, pp. 29-145). Tradução francesa: Trois essais sur la théorie de la sexualité. Paris: Gallimard, 1953.

Freud, S. (1913). Totem und tabu. Gesammelte Werke (Bd. 9). Tradução francesa: Totem et tabou. Paris: Payot, 1947.

Freud, S. (1929). Das unbehagen in der kultur. Gesammelte Werke (Bd. 14, pp. $417-$ 505). Tradução francesa: Malaise dans la civilisation. Paris: PUF, 1971. Nova edição.

Róheim, G. (1972). Origine et fonction de la culture. Paris: Gallimard. (Trabalho original publicado em 1943)

Winnicott, D. W. (1975). L'espace potentiel. In D. W. Winnicott, Jeu et réalité. Paris: Gallimard.

Recebido em 19.04.2004

Aceito em 19.05.2004 